\title{
Outcomes of Cardiac Screening in Adolescent Soccer Players
}

\author{
Aneil Malhotra, M.B., B.Chir., Ph.D., Harshil Dhutia, M.B., B.S., \\ Gherardo Finocchiaro, M.D., Sabiha Gati, M.B., B.S., Ph.D., \\ Ian Beasley, M.B., B.S., Paul Clift, M.B., B.S., M.D., Charlotte Cowie, M.B., B.S., \\ Antoinette Kenny, M.B., B.S., M.D., Jamil Mayet, M.B., B.S., M.D., \\ David Oxborough, Ph.D., Kiran Patel, M.B., B.Chir., Ph.D., \\ Guido Pieles, M.B., B.S., Ph.D., Dhrubo Rakhit, M.B., B.S., Ph.D., \\ David Ramsdale, M.B., B.S., M.D., Leonard Shapiro, M.B., B.S., M.D., \\ John Somauroo, M.B., B.S., Graham Stuart, M.B., Ch.B., \\ Amanda Varnava, M.B., Chir.B., M.D., John Walsh, M.B., B.S., D.M., \\ Zaheer Yousef, M.B., B.S., M.D., Maite Tome, M.D., Ph.D., \\ Michael Papadakis, M.B., B.S., M.D., and Sanjay Sharma, M.B., Ch.B., M.D.
}

The authors' affiliations are listed in the Appendix. Address reprint requests to Dr. Sharma at the Cardiology Clinical Academic Group, St. George's, University of London, Cranmer Terrace, London SW17 ORE, United Kingdom, or at sasharma@ sgul.ac.uk.

A list of the authors who are members of the Cardiology Consensus Group of the English Football Association is provided in the Supplementary Appendix, available at NEJM.org.

N Engl J Med 2018;379:524-34. DOI: 10.1056/NEJMoa1714719 Copyright @ 2018 Massachusetts Medical Society.

\section{ABSTRACT}

\section{BACKGROUND}

Reports on the incidence and causes of sudden cardiac death among young athletes have relied largely on estimated rates of participation and varied methods of reporting. We sought to investigate the incidence and causes of sudden cardiac death among adolescent soccer players in the United Kingdom.

\section{METHODS}

From 1996 through 2016, we screened 11,168 adolescent athletes with a mean $( \pm S D)$ age of $16.4 \pm 1.2$ years ( $95 \%$ of whom were male) in the English Football Association (FA) cardiac screening program, which consisted of a health questionnaire, physical examination, electrocardiography, and echocardiography. The FA registry was interrogated to identify sudden cardiac deaths, which were confirmed with autopsy reports.

RESULTS

During screening, 42 athletes $(0.38 \%)$ were found to have cardiac disorders that are associated with sudden cardiac death. A further 225 athletes (2\%) with congenital or valvular abnormalities were identified. After screening, there were 23 deaths from any cause, of which 8 (35\%) were sudden deaths attributed to cardiac disease. Cardiomyopathy accounted for 7 of 8 sudden cardiac deaths $(88 \%)$. Six athletes (75\%) with sudden cardiac death had had normal cardiac screening results. The mean time between screening and sudden cardiac death was 6.8 years. On the basis of a total of 118,351 person-years, the incidence of sudden cardiac death among previously screened adolescent soccer players was 1 per 14,794 person-years (6.8 per 100,000 athletes).

\section{CONCLUSIONS}

Diseases that are associated with sudden cardiac death were identified in $0.38 \%$ of adolescent soccer players in a cohort that underwent cardiovascular screening. The incidence of sudden cardiac death was 1 per 14,794 person-years, or 6.8 per 100,000 athletes; most of these deaths were due to cardiomyopathies that had not been detected on screening. (Funded by the English Football Association and others.) 
S UDDEN CARDIAC DEATH IN A SEEMINGLY healthy athlete invariably prompts discussion about possible preventative screening strategies. The absence of a systematic registry of deaths in young athletes ( $<35$ years old) has been a major obstacle to ascertaining the precise incidence of sudden cardiac death in this group; estimates vary between 0.5 and 13 deaths per 100,000 athletes, ${ }^{1,2}$ depending on the population studied and methods of data collection used. ${ }^{3}$ Furthermore, data on outcomes in adolescent athletes who have been screened for cardiovascular disease in a well-defined cohort are lacking.

The English Football Association (FA) has run a mandatory cardiac screening program for adolescent athletes in the United Kingdom since 1997, with a total of more than 11,000 athletes screened since its inception. The aim of this study was to determine the incidence and causes of sudden cardiac death in this well-defined population of previously screened soccer players.

\section{METHODS}

\section{SCREENING PROGRAM}

Between January 1, 1996, and December 31, 2016, a total of 11,168 soccer players at clubs affiliated with the FA underwent mandatory cardiovascular screening. The program encompassed all youth academy players (15 to 17 years of age) across the 92 professional clubs in the soccer league system who had excelled within the preceding 5 years. All such high-ranking players were offered a formal remunerated scholar contract (usually at the age of 16 years) with a view to progressing to a professional senior career. Written informed consent for screening was obtained from each player by the team doctor. Written informed consent from a parent or guardian was required for athletes younger than 16 years of age, in accordance with the FA governance department.

Athletes underwent assessment with a health questionnaire (Fig. S1 in the Supplementary Appendix, available with the full text of this article at NEJM.org), physical examination, 12-lead electrocardiography (ECG), and echocardiography. Mobile screening units staffed by accredited sonographers visited the clubs to conduct the evaluations, and the results were reviewed by an expert regional cardiologist who was a member of the FA-approved cardiology consensus panel.
A formal report was sent to the FA medical department, in which each athlete was classified in one of three categories on the basis of the evaluation: normal; further evaluation needed, if an abnormality was detected that required further investigation to confirm or refute the presence of cardiac disease; or cardiac disease detected. The last category was subclassified into disorders that are associated with sudden cardiac death or those encompassing congenital septal and valvular conditions.

Further investigations were performed at regional specialist centers. Athletes with T-wave inversion, abnormally enlarged cardiac dimensions, or a low ejection fraction and those fulfilling echocardiographic criteria for left ventricular noncompaction underwent maximal exercise stress testing, 24-hour Holter monitoring, and cardiovascular magnetic resonance imaging (MRI). Athletes with a prolonged QT interval underwent exercise stress testing and 24-hour Holter monitoring, and athletes with a Wolff-ParkinsonWhite ECG pattern were risk-stratified on the basis of an exercise test and an electrophysiological study. From 2012 onward, there was sufficient evidence indicating that among black athletes, anterior T-wave inversion was a common variant that was not associated with structural heart disease or serious cardiac arrhythmias ${ }^{4}$; therefore, asymptomatic black athletes with this repolarization abnormality did not undergo further investigation unless the echocardiogram was abnormal. ${ }^{5}$ In 2013, we ceased to investigate athletes who fulfilled echocardiographic criteria for left ventricular noncompaction but had a normal ECG and normal cardiac function. ${ }^{6}$ The results of all the investigations were reported back to the FA headquarters and reviewed independently by the first and last authors.

\section{DIAGNOSIS OF DISORDERS ASSOCIATED WITH SUDDEN CARDIAC DEATH}

The diagnosis of hypertrophic cardiomyopathy was based on a left ventricular wall thickness of $15 \mathrm{~mm}$ or greater in any myocardial segment on echocardiography or cardiovascular MRI in the absence of another condition capable of producing left ventricular hypertrophy. ${ }^{7-9}$ The diagnosis of dilated cardiomyopathy was considered if the patient had a dilated left ventricle (a left ventricular end-diastolic dimension of $>59 \mathrm{~mm}$ in males and $>53 \mathrm{~mm}$ in females) and a reduced ejection 
fraction $\left(<52 \%\right.$ in males and $<54 \%$ in females). ${ }^{10,11}$ The diagnosis of arrhythmogenic right ventricular cardiomyopathy was based on published criteria. ${ }^{12,13}$ The diagnosis of long-QT syndrome was based on a corrected QT (QTc) interval of $500 \mathrm{msec}$ or greater or of 470 to $490 \mathrm{msec}$ in association with notched $\mathrm{T}$ waves in at least three leads, paradoxical prolongation of the QT interval with exercise, or a positive genetic test. $^{14,15}$ Identification of the Wolff-ParkinsonWhite ECG pattern was based on findings of a short PR interval and a slurred upstroke to the QRS complex.

RECOMMENDATIONS FOR FOLLOW-UP ASSESSMENTS OR EXCLUSION FROM PLAY

Some of the screened athletes had abnormal T-wave inversion but structurally normal hearts, and others had borderline-abnormal cardiac dimensions but no other features to support the diagnosis of cardiomyopathy. These athletes were investigated with ECG and echocardiography performed every year and cardiovascular MRI performed every 2 years. Athletes with congenital valvular abnormalities or septal defects were monitored with annual ECG and echocardiography.

Athletes with cardiac disorders that are associated with sudden cardiac death were advised not to compete and were discharged into the care of the National Health Service. Decisions to disqualify such athletes were made by the FA cardiology consensus panel after discussions in accordance with current exercise recommendations of the European Society of Cardiology and the American Heart Association. ${ }^{16-18}$ The decision was relayed to the player in the presence of the player's parent or guardian and the club doctor by the regional cardiologist.

\section{OUTCOMES}

Calculation of the follow-up period per athlete was based on the number of years of competition within the FA, which was determined from the FA registry of players. Deaths among athletes were ascertained through the development of a database that was compiled from voluntary reports to the FA. A second method to ascertain the number of deaths was through a secure survey that was sent to health professionals at each of the 92 FA-affiliated clubs, asking specifically about deaths from any cause. In addition, regular Internet searches had been performed since
2005, with the use of three different search engines (Google, Yahoo, and MSN search [Bing]) and at least 16 keywords (student, athlete, collapsed, died, death, heart, cardiac, arrest, attack, soccer, running, school, unknown, college, defibrillator, and saved).

Death certificates were obtained from the U.K. government for all deceased persons in the cohort to ascertain the causes of death, which were categorized broadly as accidental, suicide, drugrelated, cancer, or cardiac causes. Autopsy data were available in all cases of sudden cardiac death, and diagnoses were based on previously established pathological criteria in conjunction with consultation with an expert cardiac pathologist. ${ }^{19}$

Data on survival status during the screening program over the 20-year period among athletes who had diagnoses of cardiac disorders that are associated with sudden cardiac death were obtained from attending cardiologists, most of whom were part of the expert FA consensus panel.

\section{RESULTS}

\section{FURTHER EVALUATION AFTER SCREENING}

The mean $( \pm S D)$ age of the 11,168 soccer players who underwent cardiovascular screening was $16.4 \pm 1.2$ years; 10,581 ( $95 \%)$ of the athletes were male. In the entire cohort, 830 athletes (7\%) underwent further investigation after preliminary assessment. Among these athletes, 104 (0.9\%) reported symptoms that were deemed noncardiac in origin after assessment by a cardiologist. Among the remaining 726 athletes, 292 (3\% of the total cohort) underwent investigation for T-wave inversion (anterior [153], inferior or lateral [114], or widespread [25]). A total of 25 athletes $(0.2 \%)$ underwent investigation for a prolonged QTc interval. A further 409 athletes (4\%) underwent cardiovascular MRI because of ventricular remodeling consistent with cardiomyopathy. ${ }^{9}$ Specifically, 229 athletes (2\%) had a left ventricular wall thickness of $13 \mathrm{~mm}$ or greater; $106(0.9 \%)$ had an enlarged left ventricular cavity with a borderline-low ejection fraction (of 50 to $52 \%)^{10}$; 80 athletes $(0.7 \%)$ had a suspected right ventricular regional wall-motion abnormality, and 19 $(0.2 \%)$ had increased left ventricular trabeculation and a mildly reduced ejection fraction (of $\leq 50 \%$ ). ${ }^{6}$ Twenty-five athletes had abnormal T-wave inversion and enlarged cardiac dimensions. 


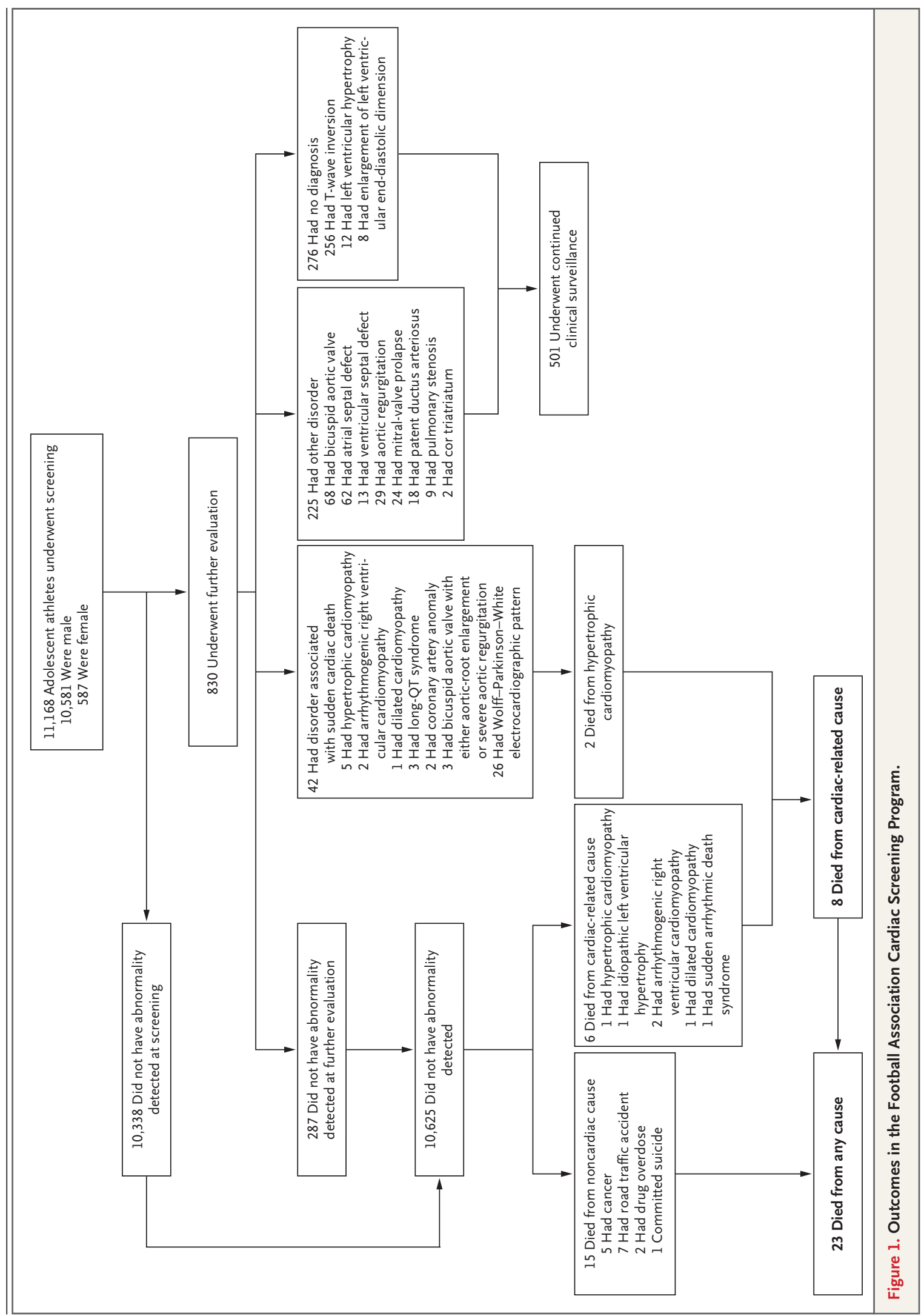

N ENGLJ MED 379;6 NEJM.ORG AUGUST 9, 2018

The New England Journal of Medicine 


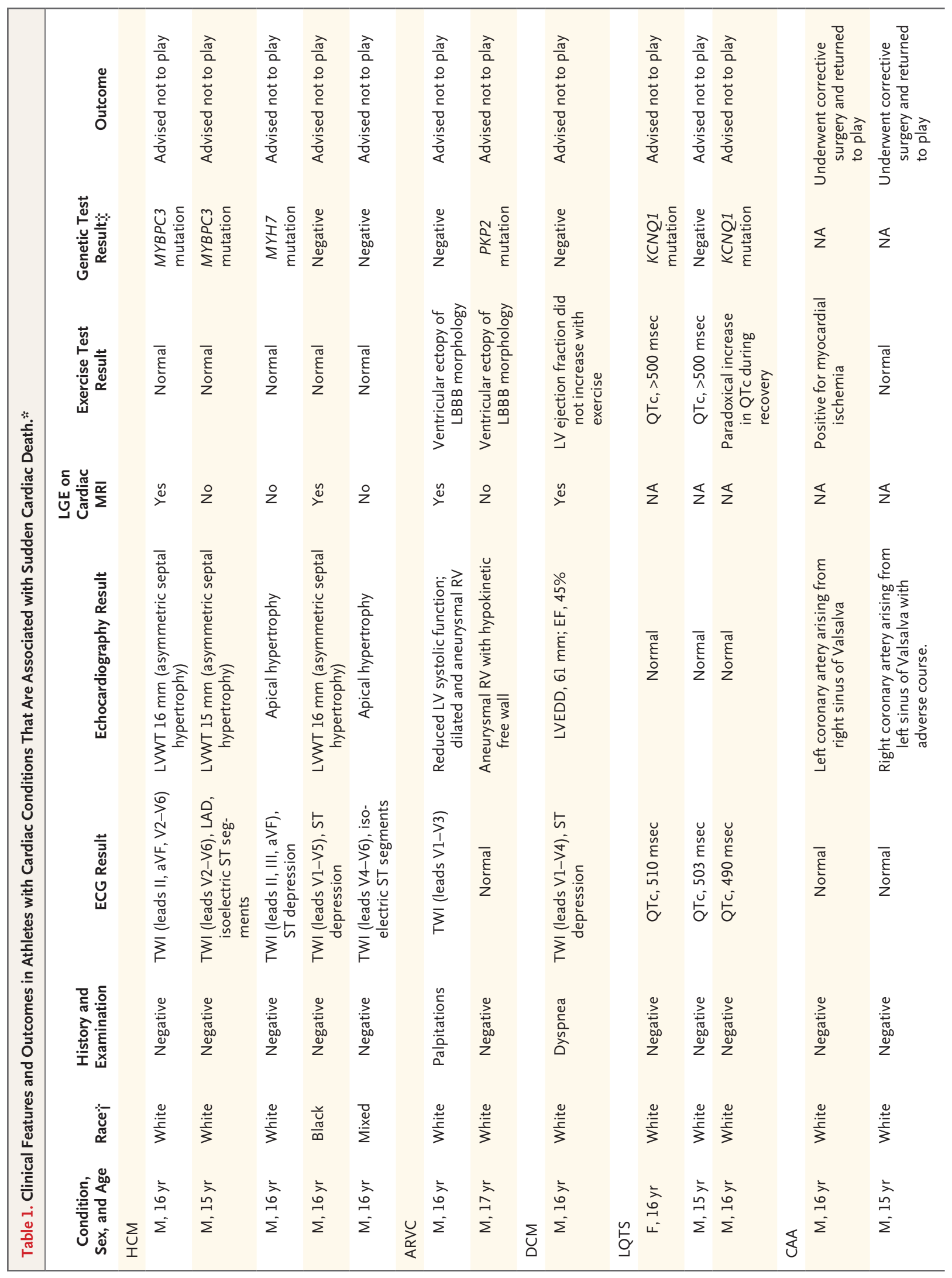




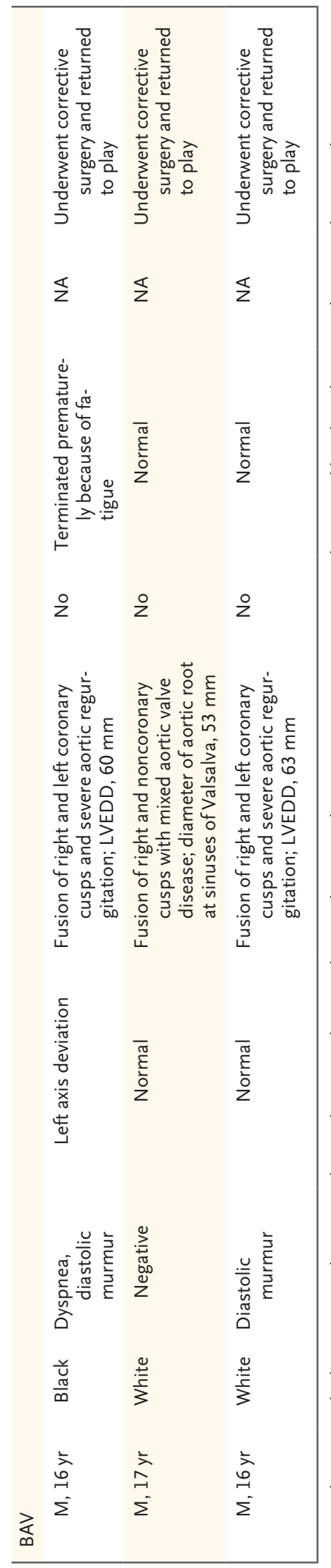

\section{DETECTION OF CARDIAC DISEASE}

A total of 42 athletes $(0.38 \%)$ were found to have cardiac disorders that are associated with sudden cardiac death (Fig. 1 and Table 1). Five (0.04\%) had a diagnosis of hypertrophic cardiomyopathy, $2(0.02 \%)$ of arrhythmogenic right ventricular cardiomyopathy, ${ }^{12}$ and 1 (0.01\%) of dilated cardiomyopathy. Three athletes $(0.03 \%)$ had a diagnosis of long-QT syndrome. Two athletes $(0.02 \%)$ had a diagnosis of an anomalous origin of a coronary artery, and $3(0.03 \%)$ were found to have a bicuspid aortic valve associated with either aortic-root enlargement of $50 \mathrm{~mm}$ or greater (1) or severe aortic regurgitation (2). A total of 26 $(0.23 \%)$ athletes had the Wolff-Parkinson-White ECG pattern (Table S1 in the Supplementary Appendix).

Among the 42 athletes with cardiac disorders that are associated with sudden cardiac death, 2 (5\%) had symptoms, 1 (2\%) had an abnormality detected on cardiac examination, and 1 (2\%) had both symptoms and an abnormality detected on examination (Table 2). Abnormal ECGs were obtained in 36 of these athletes (86\%), and abnormal echocardiograms in 12 (29\%).

There were 225 athletes (2\%) with other cardiac disorders, including congenital septal and valvular abnormalities (Fig. 1). The diagnoses in all of these athletes were made with the use of echocardiography; 48 of the athletes (21\%) had an abnormal ECG, and 74 (33\%) had an abnormality detected on examination (Table 2).

\section{INTERVENTIONS AND OUTCOMES}

Athletes with a diagnosis of cardiomyopathy (8) or long-QT syndrome (3) were advised against participation in competitive soccer. None of the athletes with cardiomyopathy were deemed to have a sufficiently high-risk profile to warrant a prophylactic implantable cardioverter-defibrillator. ${ }^{7,20,21}$ The 3 athletes with long-QT syndrome began treatment with beta-blockers. Both athletes with anomalous coronary-artery origins underwent corrective surgery and returned to play. The 3 athletes with bicuspid aortic valves underwent surgical intervention for aortic-root dilatation (1) or severe aortic regurgitation (2) and returned to play (Table 1). All 26 athletes with the WolffParkinson-White ECG pattern underwent risk stratification, and 24 underwent ablation before returning to play. The remaining 2 athletes with the Wolff-Parkinson-White pattern were deemed 


\begin{tabular}{|c|c|c|c|c|c|}
\hline \multirow[t]{2}{*}{ Condition } & \multirow[t]{2}{*}{ No. of Athletes } & \multicolumn{4}{|c|}{ No. of Athletes with Abnormal Result } \\
\hline & & History & Examination & ECG & Echocardiography \\
\hline Any cardiac condition & 267 & 6 & 76 & 84 & 237 \\
\hline Condition associated with sudden cardiac death & 42 & 3 & 2 & 36 & 12 \\
\hline Hypertrophic cardiomyopathy & 5 & 0 & 0 & 5 & 5 \\
\hline Arrhythmogenic right ventricular cardiomyopathy & 2 & 1 & 0 & 1 & 2 \\
\hline Dilated cardiomyopathy & 1 & 1 & 0 & 1 & 1 \\
\hline Coronary-artery anomalies & 2 & 0 & 0 & 0 & 2 \\
\hline Bicuspid aortic valve-associated disease* & 3 & 1 & 2 & 0 & 3 \\
\hline Long-QT syndrome & 3 & 0 & 0 & 3 & 0 \\
\hline Wolff-Parkinson-White ECG pattern & 26 & 0 & 0 & 26 & 0 \\
\hline Other cardiac condition & 225 & 3 & 74 & 48 & 225 \\
\hline Bicuspid aortic valve & 68 & 1 & 32 & 15 & 68 \\
\hline Atrial septal defect & 62 & 1 & 6 & 26 & 62 \\
\hline Aortic regurgitation & 29 & 0 & 16 & 2 & 29 \\
\hline Mitral-valve prolapse & 24 & 0 & 12 & 3 & 24 \\
\hline Patent ductus arteriosus & 18 & 0 & 1 & 1 & 18 \\
\hline Ventricular septal defect & 13 & 0 & 3 & 1 & 13 \\
\hline Pulmonary stenosis & 9 & 1 & 4 & 0 & 9 \\
\hline Cor triatriatum & 2 & 0 & 0 & 0 & 2 \\
\hline
\end{tabular}

* Bicuspid aortic valve-associated disease includes bicuspid aortic valve with either aortic-root enlargement or severe aortic regurgitation.

to have low-risk accessory conduction pathways that were not ablated, and they continued to compete (Table S1 in the Supplementary Appendix).

Of the 42 athletes who, during screening, received diagnoses of cardiac disorders that are associated with sudden cardiac death, 40 (95\%) were alive at the end of the study period. Two athletes with a diagnosis of hypertrophic cardiomyopathy continued to compete despite medical advice and died subsequently during intensive exercise.

Among the 225 athletes with other cardiac disorders, 7 with an atrial septal defect and 1 with a ventricular septal defect had hemodynamic indications to warrant percutaneous closure before returning to play. The remaining 217 athletes (97\%) had mild disease and were permitted to compete. We could not establish a cardiac diagnosis in 276 athletes (2\%) who had abnormal T-wave inversion or borderline abnormal cardiac dimensions. All these athletes continued to compete but remained under clinical surveillance.

\section{ALL-CAUSE MORTALITY}

Of the 92 professional clubs, 86 (93\%) responded to the questionnaire regarding all-cause mortality. During a mean follow-up period of $10.6 \pm 8.3$ years, there were 23 deaths. The causes of death included road traffic accidents (7 deaths [30\%]), cancer (5 [22\%]), drug overdose (2 [9\%]), and suicide (1 [4\%]). Cardiac disorders accounted for 8 deaths (35\%), all of which were sudden and occurred during exercise (Fig. 2).

\section{SUDDEN CARDIAC DEATHS}

Autopsy data were available for all sudden cardiac deaths. Among the athletes who died from cardiac disorders, the mean time between screening and sudden death was 6.8 years (range, 0.1 to 13.2). Cardiomyopathies were the most common cause of death and accounted for 7 of 8 ( $88 \%)$ sudden cardiac deaths (Table 3). There were a total of 118,351 person-years of follow-up over the 20-year study period. The resulting overall incidence of sudden cardiac death among ado- 


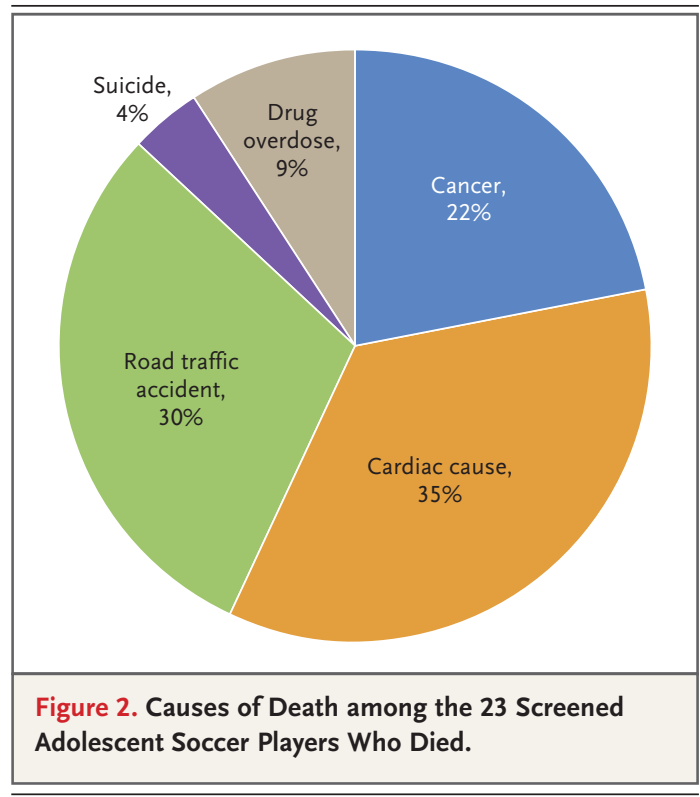

lescent soccer players was 1 per 14,794 personyears, or 6.8 per 100,000 athletes.

Of the 8 sudden cardiac deaths, 6 (75\%) were in athletes who had normal findings during preliminary screening (Fig. 1 and Table 3). Variation in test interpretation could have accounted for the normal findings. Therefore, 50 deidentified ECGs and corresponding echocardiograms from the cohort were analyzed by two independent experts in inherited cardiac diseases who were unaware of the outcomes. The ECGs and echocardiograms were from 45 athletes whose results had been interpreted as normal, including the 6 decedents, and 5 athletes with abnormal results, including 1 athlete each with a diagnosis of arrhythmogenic right ventricular cardiomyopathy, dilated cardiomyopathy, hypertrophic cardiomyopathy, long QT interval, and the Wolff-Parkinson-White ECG pattern. Blind reading showed $100 \%$ agreement between the two reviewers for the 6 decedents with normal results (Table 3).

\section{COST OF DIAGNOSIS}

On the basis of the U.K. National Health Service tariffs, ${ }^{22}$ the cost of preliminary investigation with consultation ( $€ 160$ [\$213 in U.S. dollars]), ECG ( $€ 25$ [\$33]), and echocardiography ( $€ 72$ [\$96]) would amount to $£ 257$ (\$342) per athlete, resulting in an initial cost of screening 11,168 athletes of $£ 2,870,176(\$ 3,817,334)$. The cost of further investigating 830 athletes was $£ 375,587$
$(\$ 499,531)$, with a total estimated outlay of $£ 3,245,763(\$ 4,316,865)$. The cost to detect serious cardiac disease associated with sudden cardiac death (42 athletes) was $€ 77,280$ (\$102,782) per case, and the cost to identify any cardiac disorder (267 athletes) was $£ 12,156(\$ 16,167)$ per case.

\section{DISCUSSION}

We report the outcomes of cardiovascular screening of adolescent soccer players, determined with the use of data from the FA in the United Kingdom. The prevalence of disorders associated with sudden cardiac death in young athletes was $0.38 \%$, which is similar to that reported in other screening programs. ${ }^{23-25}$ Congenital septal and minor valvular disorders were detected in an additional $2 \%$ of the athletes, leading to an overall prevalence of $2.4 \%$ for all cardiac conditions.

In this cohort, electrical diseases accounted for 29 (69\%) of the 42 cases of cardiac disorders that are associated with sudden cardiac death, whereas the primary cardiomyopathies accounted for only 8 (19\%) of these cases. Anomalous coronary-artery origins accounted for $2(5 \%)$ of the cases but were almost certainly underrepresented because of the limitations of echocardiography in detecting this type of disorder. The remaining $3(7 \%)$ of the 42 cases were due to advanced aortic-valve disease. History, findings on physical examination, and ECG were abnormal in $7 \%, 5 \%$, and $86 \%$, respectively, of athletes with cardiac disorders associated with sudden cardiac death.

Hypertrophic cardiomyopathy was the most commonly detected cardiomyopathy, and all 5 athletes in whom this condition was detected had an abnormal ECG and echocardiogram. The prevalence of hypertrophic cardiomyopathy among these elite adolescent soccer players was 1 in 1861 athletes (including 1 case not detected by screening), which is considerably lower than that reported in the general population, raising the possibility that athletes with a more advanced phenotype at this age may have been selected out of competition because of reduced cardiorespiratory capacity. ${ }^{26,27}$ Age-related penetrance of hypertrophic cardiomyopathy is also an important consideration, since in many affected persons the disease is not expressed during adolescence. ${ }^{28-33}$ The prevalence of arrhythmogenic right ventric- 


\begin{tabular}{|c|c|c|c|c|c|c|c|}
\hline $\begin{array}{l}\text { Athlete } \\
\text { No. }\end{array}$ & $\begin{array}{l}\text { Sex and } \\
\text { Age }\end{array}$ & Race* & $\begin{array}{l}\text { Years from } \\
\text { Screening } \\
\text { to Death }\end{array}$ & Diagnosis & $\begin{array}{l}\text { Initial Screening } \\
\text { Result }\end{array}$ & $\begin{array}{l}\text { Blind Reading } \\
\text { (Reviewer 1) }\end{array}$ & $\begin{array}{c}\text { Blind Reading } \\
\text { (Reviewer 2) }\end{array}$ \\
\hline 1 & $\mathrm{M}, 16.8 \mathrm{yr}$ & Black & 0.1 & Idiopathic left ventricular hypertrophy & Negative & Negative & Negative \\
\hline 2 & $\mathrm{M}, 16.6 \mathrm{yr}$ & Mixed & 1.0 & Hypertrophic cardiomyopathy & $\begin{array}{l}\text { Abnormal ECG and } \\
\text { echocardiogram }\end{array}$ & NA & NA \\
\hline 3 & $\mathrm{M}, 16.6 \mathrm{yr}$ & Black & 3.3 & Hypertrophic cardiomyopathy & Negative & Negative & Negative \\
\hline 4 & $\mathrm{M}, 16.3 \mathrm{yr}$ & Black & 7.7 & Dilated cardiomyopathy & Negative & Negative & Negative \\
\hline 5 & $\mathrm{M}, 17.0 \mathrm{yr}$ & White & 7.9 & $\begin{array}{l}\text { Arrhythmogenic right ventricular } \\
\text { cardiomyopathy }\end{array}$ & Negative & Negative & Negative \\
\hline 6 & $\mathrm{M}, 17.2 \mathrm{yr}$ & White & 9.7 & $\begin{array}{l}\text { Arrhythmogenic right ventricular } \\
\text { cardiomyopathy }\end{array}$ & Negative & Negative & Negative \\
\hline 7 & $\mathrm{M}, 15.7 \mathrm{yr}$ & White & 11.5 & Hypertrophic cardiomyopathy & $\begin{array}{l}\text { Abnormal ECG and } \\
\text { echocardiogram }\end{array}$ & NA & NA \\
\hline 8 & $\mathrm{M}, 16.8 \mathrm{yr}$ & White & 13.2 & Sudden arrhythmic death syndrome & Negative & Negative & Negative \\
\hline
\end{tabular}

* Race was reported by the athlete or the parent or guardian.

ular cardiomyopathy was 1 in 2792 athletes; this disorder has a highly variable clinical course, and the mean age at presentation is $31 \pm 13$ years. ${ }^{34}$ Exercise has been shown to accelerate the phenotypic manifestations of this condition, ${ }^{35,36}$ and years of intensive training regimes may well contribute to the unmasking of phenotypes that could not be detected during adolescence.

Of the seven athletes who died suddenly from cardiomyopathy, five (71\%) had a normal ECG and echocardiogram at a mean age of 16 years. Screening at this age seems logistically appropriate, given that most people will be postpubertal and will have overt evidence of any electrical or structural cardiac abnormalities. However, this study shows that screening during late adolescence will fail to detect a substantial proportion of athletes who have or will eventually have a cardiomyopathy, either because the disease is not yet manifest or because ECG and echocardiography are not sensitive enough to detect early disease in some adolescents.

This systematic study revealed that the incidence of sudden cardiac death among screened 16-year-old soccer players was approximately 1 per 14,800 person-years, or 6.8 per 100,000 athletes. This figure is considerably higher than previous estimates among athletes who have been screened with the use of history and physical examination alone or who have not undergone cardiac screening. ${ }^{1-3,37-41}$ Sudden cardiac death may be more common in some sports than in others; these results in adolescent soccer players are similar to findings previously reported in male basketball players. ${ }^{3}$ The National Collegiate Athletic Association in the United States adopted a policy in 2014 requiring all affiliated institutions to report cases of catastrophic injury or death. Such mandatory reporting initiatives across other sporting organizations would offer an important source of prospective data in already well-defined populations.

Several limitations of our study should be noted. For our data, we relied on voluntary reporting of sudden cardiac deaths by clubs and on retrospective recall. Although we confirmed all sudden cardiac deaths with death certificates and autopsy reports, it is possible that we did not capture all cases. Our results therefore represent the minimum incidence of sudden cardiac death among screened adolescent soccer players. The end point of our study was sudden death, and therefore we are unable to comment on the number of athletes in whom a quiescent cardiomyopathy may have developed after the initial screen or who survived a sudden cardiac arrest. Finally, our study included only adolescent soccer players of the highest ability and may underestimate the burden of cardiac disorders or prevalence of sudden cardiac death among non-elite or older players.

In conclusion, we investigated the results of 
cardiovascular screening of a large cohort of adolescent soccer players in the United Kingdom. Diseases associated with sudden cardiac death, the majority of them electrical cardiac disorders, were identified in $0.38 \%$ of participants. The incidence of sudden cardiac death among these previously screened athletes was approximately 1 per 14,800 person-years, or 6.8 per 100,000 athletes. Most of these deaths were due to cardiomyopathies that were not detected on screening.

Supported by the English Football Association, Cardiac Risk in the Young (to Drs. Malhotra and Dhutia), and the Charles Wolfson charitable trust (to Dr. Finocchiaro).

Disclosure forms provided by the authors are available with the full text of this article at NEJM.org.

We thank Kerrie Bayliss and Sue Cheadle for their administrative assistance.

\section{APPENDIX}

The authors' affiliations are as follows: the Cardiology Clinical Academic Group, St. George's, University of London (A.M., H.D., G.F., S.G., M.T., M.P., S.S.), the Department of Sports Medicine, Bartholomew's and London Hospital (I.B.), and the Department of Cardiology, Imperial College NHS Trust (J.M., A.V.), London, the Football Association, Burton Upon Trent (A.M., C.C.), the Department of Cardiology, Queen Elizabeth Hospital, Birmingham (P.C.), the Department of Cardiology, Freeman Hospital, Newcastle Upon Tyne (A.K.), the Faculty of Science, Liverpool John Moores University (D.O., J.S.), and the Department of Cardiology, Liverpool Heart and Chest Hospital (D. Ramsdale), Liverpool, the Department of Cardiology, Good Hope Hospital, Sutton Coldfield (K.P.), Bristol Heart Institute, Bristol (G.P., G.S.), University Hospital Southampton, Southampton (D. Rakhit), the Department of Cardiology, Papworth Hospital, Papworth (L.S.), Nottingham City Hospital, Nottingham (J.W.), and the University Hospital of Wales, Cardiff (Z.Y.) — all in the United Kingdom.

\section{REFERENCES}

1. Maron BJ, Gohman TE, Aeppli D. Prevalence of sudden cardiac death during competitive sports activities in Minnesota high school athletes. J Am Coll Cardiol 1998;32:1881-4.

2. Eckart RE, Scoville SL, Campbell CL et al. Sudden death in young adults: a 25 year review of autopsies in military re cruits. Ann Intern Med 2004;141:829-34.

3. Harmon KG, Asif IM, Klossner D, Drezner JA. Incidence of sudden cardiac death in National Collegiate Athletic As sociation athletes. Circulation 2011;123: 1594-600.

4. Papadakis M, Carre F, Kervio G, et al. The prevalence, distribution, and clinica outcomes of electrocardiographic repolarization patterns in male athletes of African/ Afro-Caribbean origin. Eur Heart J 2011; 32:2304-13.

5. Drezner JA, Ackerman MJ, Anderson J, et al. Electrocardiographic interpretation in athletes: the 'Seattle criteria.' Br J Sports Med 2013;47:122-4.

6. Gati S, Chandra N, Bennett RL, et al. Increased left ventricular trabeculation in highly trained athletes: do we need more stringent criteria for the diagnosis of left ventricular noncompaction in athletes? Heart 2013;99:401-8.

7. Elliott PM, Anastasakis A, et al. 2014 ESC guidelines on diagnosis and management of hypertrophic cardiomyopathy: the Task Force for the Diagnosis and Management of Hypertrophic Cardiomyopathy of the European Society of Cardiology (ESC). Eur Heart J 2014;35:2733-79.

8. Gersh BJ, Maron BJ, Bonow RO, et al. 2011 ACCF/AHA guideline for the diagnosis and treatment of hypertrophic cardiomyopathy: a report of the American College of Cardiology Foundation/American
Heart Association Task Force on Practice Guidelines. J Am Coll Cardiol 2011; 58(25):e212-e260.

9. Sharma S, Maron BJ, Whyte G, Firoozi S, Elliott PM, McKenna WJ. Physiologic limits of left ventricular hypertrophy in elite junior athletes: relevance to differential diagnosis of athlete's heart and hypertrophic cardiomyopathy. J Am Coll Cardiol 2002;40:1431-6.

10. Lang RM, Badano LP, Mor-Avi V, et al. Recommendations for cardiac chamber quantification by echocardiography in adults: an update from the American Society of Echocardiography and the European Association of Cardiovascular Imaging. J Am Soc Echocardiogr 2015;28(1): 1-39.e14.

11. Makan J, Sharma S, Firoozi S, Whyte G, Jackson PG, McKenna WJ. Physiological upper limits of ventricular cavity size in highly trained adolescent athletes. Heart 2005;91:495-9.

12. Marcus FI, McKenna WJ, Sherrill D, et al. Diagnosis of arrhythmogenic right ventricular cardiomyopathy/dysplasia: proposed modification of the Task Force Criteria. Circulation 2010;121:1533-41.

13. McKenna WJ, Thiene G, Nava A, et al. Diagnosis of arrhythmogenic right ventricular dysplasia/cardiomyopathy. $\mathrm{Br}$ Heart J 1994;71:215-8.

14. Schwartz PJ, Crotti L. QTc behavior during exercise and genetic testing for the long-QT syndrome. Circulation 2011;124: 2181-4.

15. Basavarajaiah S, Wilson M, Whyte G, Shah A, Behr E, Sharma S. Prevalence and significance of an isolated long QT interval in elite athletes. Eur Heart J 2007;28: 2944-9.

16. Pelliccia A, Fagard R, Bjфrnstad $\mathrm{HH}$, et al. Recommendations for competitive sports participation in athletes with cardiovascular disease: a consensus document from the Study Group of Sports Cardiology of the Working Group of Cardiac Rehabilitation and Exercise Physiology and the Working Group of Myocardial and Pericardial Diseases of the European Society of Cardiology. Eur Heart J 2005;26:1422-45.

17. Levine BD, Baggish AL, Kovacs RJ, Link MS, Maron MS, Mitchell JH. Eligibility and disqualification recommendations for competitive athletes with cardiovascular abnormalities: task force 1: classification of sports: dynamic, static, and impact: a scientific statement from the American Heart Association and American College of Cardiology. J Am Coll Cardiol 2015;66: 2350-5.

18. Thompson PD, Myerburg RJ, Levine BD, Udelson JE, Kovacs RJ. Eligibility and disqualification recommendations for competitive athletes with cardiovascular abnormalities: task force 8: coronary artery disease: a scientific statement from the American Heart Association and American College of Cardiology. Circulation 2015;132(22):e310-e314.

19. Finocchiaro G, Papadakis M, Robertus JL, et al. Etiology of sudden death in sports: insights from a United Kingdom regional registry. J Am Coll Cardiol 2016; 67:2108-15.

20. Maron BJ, Maron MS. Contemporary strategies for risk stratification and prevention of sudden death with the implantable defibrillator in hypertrophic cardiomyopathy. Heart Rhythm 2016;13:1155-65. 21. Calkins H, Corrado D, Marcus F. Risk stratification in arrhythmogenic right ventricular cardiomyopathy. Circulation 2017; 136:2068-82. 
22. Dhutia H, Malhotra A, Gabus V, et al. Cost implications of using different ECG criteria for screening young athletes in the United Kingdom. J Am Coll Cardiol 2016;68:702-11.

23. Corrado D, Basso C, Pavei A, Michieli P, Schiavon M, Thiene G. Trends in sudden cardiovascular death in young competitive athletes after implementation of a preparticipation screening program. JAMA 2006;296:1593-601.

24. Maron BJ, Thompson PD, Ackerman $\mathrm{MJ}$, et al. Recommendations and considerations related to preparticipation screening for cardiovascular abnormalities in competitive athletes: 2007 update: a scientific statement from the American Heart Association Council on Nutrition, Physical Activity, and Metabolism: endorsed by the American College of Cardiology Foundation. Circulation 2007;115:1643-55.

25. Fuller CM, McNulty CM, Spring DA, et al. Prospective screening of 5,615 high school athletes for risk of sudden cardiac death. Med Sci Sports Exerc 1997;29:1131-8. 26. Basavarajaiah S, Wilson M, Whyte G, Shah A, McKenna W, Sharma S. Prevalence of hypertrophic cardiomyopathy in highly trained athletes: relevance to pre-participation screening. J Am Coll Cardiol 2008; 51:1033-9.

27. Harmon KG, Zigman M, Drezner JA. The effectiveness of screening history, physical exam, and ECG to detect potentially lethal cardiac disorders in athletes: a systematic review/meta-analysis. J Electrocardiol 2015;48:329-38.
28. Maron BJ, Olivotto I, Spirito P, et al. Epidemiology of hypertrophic cardiomyopathy-related death: revisited in a large non-referral-based patient population. Circulation 2000;102:858-64.

29. Maron BJ. Hypertrophic cardiomyopathy: a systematic review. JAMA 2002;287: 1308-20.

30. Niimura H, Bachinski LL, Sangwatanaroj S, et al. Mutations in the gene for cardiac myosin-binding protein $\mathrm{C}$ and lateonset familial hypertrophic cardiomyopathy. N Engl J Med 1998;338:1248-57.

31. Maron BJ, Niimura H, Casey SA, et al. Development of left ventricular hypertrophy in adults in hypertrophic cardiomyopathy caused by cardiac myosin-binding protein C gene mutations. J Am Coll Cardiol 2001;38:315-21.

32. Maron BJ, Spirito P, Wesley Y, Arce J. Development and progression of left ventricular hypertrophy in children with hypertrophic cardiomyopathy. N Engl J Med 1986;315:610-4.

33. Maron BJ, Haas TS, Ahluwalia A, Rutten-Ramos SC. Incidence of cardiovascular sudden deaths in Minnesota high school athletes. Heart Rhythm 2013;10: 374-7.

34. McNally E, MacLeod H, DellefaveCastillo L. Arrhythmogenic right ventricular cardiomyopathy. GeneReviews. April 18, 2005 (updated May 25, 2017) (https:/ www.ncbi.nlm.nih.gov/books/NBK1131/). 35. Ruwald AC, Marcus F, Estes NA III, et al. Association of competitive and recreational sport participation with cardiac events in patients with arrhythmogenic right ventricular cardiomyopathy: results from the North American multidisciplinary study of arrhythmogenic right ventricular cardiomyopathy. Eur Heart J 2015;36:173543.

36. James CA, Bhonsale A, Tichnell C, et al. Exercise increases age-related penetrance and arrhythmic risk in arrhythmogenic right ventricular dysplasia/cardiomyopathyassociated desmosomal mutation carriers. J Am Coll Cardiol 2013;62:1290-7.

37. Maron BJ, Doerer JJ, Haas TS, Tierney DM, Mueller FO. Sudden deaths in young competitive athletes: analysis of 1866 deaths in the United States, 1980-2006. Circulation 2009;119:1085-92.

38. Van Camp SP, Bloor CM, Mueller FO, Cantu RC, Olson HG. Nontraumatic sports death in high school and college athletes. Med Sci Sports Exerc 1995;27:641-7.

39. Drezner JA, Harmon KG, Marek JC. Incidence of sudden cardiac arrest in Minnesota high school student athletes: the limitations of catastrophic insurance claims. J Am Coll Cardiol 2014;63:1455-6. 40. Drezner JA, Rogers KJ. Sudden cardiac arrest in intercollegiate athletes: detailed analysis and outcomes of resuscitation in nine cases. Heart Rhythm 2006;3:755-9.

41. Harmon KG, Drezner JA, Wilson MG, Sharma S. Incidence of sudden cardiac death in athletes: a state-of-the-art review. Heart 2014;100:1227-34.

Copyright @ 2018 Massachusetts Medical Society. you test your diagnostic skills anytime, anywhere. The Image Challenge app randomly selects from 300 challenging clinical photos published in NEJM, with a new image added each week. View an image, choose your answer, get immediate feedback, and see how others answered.

The Image Challenge app is available at the iTunes App Store. 